\title{
Salmonella Enterica Serovar Typhimurium DT104 Invasion is Not Enhanced by Sub-Inhibitory Concentrations of the Antibiotic Florfenicol
}

\author{
Brian W. Brunelle ${ }^{1 *}$, Shawn M.D. Bearson ${ }^{1}$ and Bradley L. Bearson ${ }^{2}$
}

${ }^{1}$ Food Safety and Enteric Pathogens Research Unit, USDA, ARS, National Animal Disease Center, Ames, IA 50010

${ }^{2}$ Agroecosystems Management Research Unit, USDA, ARS, National Laboratory for Agriculture and the Environment, Ames, IA 50011

\begin{abstract}
The incidence of multi-drug resistant Salmonella has increased globally over the past several decades and has become a major public health concern. Isolates of Salmonella enterica serovar Typhimurium DT104 are resistant to five or more antibiotics, including florfenicol, and have been associated with enhanced virulence in livestock and humans. Because sub-inhibitory concentrations of some antibiotics have been found to modulate invasion of certain bacteria under specific conditions, the effect of florfenicol on S. Typhimurium DT104 invasion was evaluated. Three clinical bovine isolates were exposed to sub-inhibitory concentrations of florfenicol for 30 minutes to establish the initial response to the antibiotic. HEp-2 cellular invasion assays, as well as expression analyses of invasion-related genes, demonstrated that the invasiveness of the S. Typhimurium DT104 isolates was not enhanced after exposure to sub-inhibitory concentrations of florfenicol. These results suggest that cattle and swine can be treated with florfenicol for respiratory illness without exacerbating Salmonella Typhimurium DT104 virulence in carrier animals.
\end{abstract}

Keywords: Salmonella Typhimurium DT104; Florfenicol; Subinhibitory; Invasion; Virulence, FloR

\section{Introduction}

Multi-drug resistant Salmonella enterica serovar Typhimurium DT104 isolates have increased in frequency worldwide over the past several decades [1] and have been associated with enhanced virulence in livestock and humans [2,3]. Isolates of Salmonella Typhimurium DT104 are typically resistant to ampicillin, chloramphenicol/ florfenicol, streptomycin, sulfonamides, and tetracycline, but may harbor additional resistance genes [4]. Antibiotic resistance in bacteria is problematic as treatment of an infection can be ineffective, but also because sub-inhibitory concentrations of certain antibiotics may enhance virulence in some bacteria [5]. For example, at sub-inhibitory levels, florfenicol increases the adherent phenotype of Staphylococcus aureus [6], fluoroquinolones increase expression of host-colonization factors in Clostridium difficile [7], and $\beta$-lactams increase hemolytic activity in Staphylococcus aureus [8]. Few studies have reported on the effect of sub-inhibitory concentrations of antibiotics on isolates of $S$. Typhimurium DT104, and none have examined the initial effect of florfenicol exposure.

Florfenicol is a broad-spectrum bacteriostatic antibiotic analog of chloramphenicol and is used to treat respiratory disease in cattle and swine [9]. A previous study indicated that invasion was not increased after S. Typhimurium DT104 was grown to stationary phase in the presence of florfenicol or tetracycline [10]. However, another study demonstrated that invasion was enhanced in S. Typhimurium DT104 grown to late-log phase in the absence of antibiotics and subsequently exposed to tetracycline for 30 minutes [11]. The discrepancy between these two studies regarding invasion is likely due to the different experimental conditions, which has been observed in studies of Pseudomonas aeruginosa virulence that tested the same antibiotics and found contradictory results [12]. Because florfenicol is a drug used for clinical treatment of respiratory illness in animals that are known to be asymptomatic carriers of Salmonella, it is important to determine the effect florfenicol exposure has on S. Typhimurium DT104 invasion. It is also important to evaluate the initial effect of florfenicol as this antibiotic is administered to the host only when necessary, in contrast to antibiotics used in feed that provide a constant source of exposure.
In this study, we grew S. Typhimurium DT104 to late-log phase and exposed the bacteria to florfenicol for 30 minutes to determine whether these conditions enhance invasion.

\section{Materials and Methods}

\section{Bacterial strains and florfenicol exposure}

Three isolates of Salmonella Typhimurium DT104 (\#530, 745, and 19823) originally collected from cattle were selected at random from our NADC strain library. The floR gene [13], which confers florfenicol/ chloramphenicol resistance, was deleted in isolate 745 by recombination and resulted in strain BBS $650\left(745^{\Delta f l o R}\right)$ [14]. For each experiment, a single bacterial colony from a Lennox L (LB) agar plate (Invitrogen, Carlsbad, CA) was selected and grown in LB broth under agitation for 6 hours at $37^{\circ} \mathrm{C}$. A 1:1000 dilution of the 6 hour culture was made in $\mathrm{LB}$ and grown statically to stationary phase at $37^{\circ} \mathrm{C}$ overnight. A $1: 100$ dilution of the overnight culture was made in LB containing $1 \% \mathrm{NaCl}$ and divided into $16 \times 100$ glass tubes. To induce invasion [15], these cultures were grown statically for 3 hours at $37^{\circ} \mathrm{C}$ until late-log phase. Florfenicol (Nuflor, Schering Plough Animal Health) was added at final concentrations of $0,1,5$, or $30 \mu \mathrm{g} / \mathrm{ml}$, and the cultures were incubated statically for 30 minutes at $37^{\circ} \mathrm{C}: 0 \mu \mathrm{g} / \mathrm{ml}$ was the control, $1 \mu \mathrm{g} / \mathrm{ml}$ was sub-inhibitory for growth for all strains, $5 \mu \mathrm{g} / \mathrm{ml}$ was sub-inhibitory for strains 530, 745, and 19823 but was inhibitory for $745^{\triangle f l o R}$, and $30 \mu \mathrm{g} / \mathrm{ml}$ was inhibitory for all strains. The invasion and gene expression results were based on a minimum of 4 experiments using each strain.

*Corresponding author: Brian Brunelle, PhD, Food Safety and Enteric Pathogens Research Unit, National Animal Disease Center, P.O. Box 70, Ames, IA 500100070, Tel: 515.337.7612; Fax: 515.337.6190; E-mail: brian.brunelle@ars.usda.gov

Received February 11, 2011; Accepted March 04, 2011; Published March 08, 2011

Citation: Brunelle BW, Bearson SMD, Bearson BL (2011) Salmonella Enterica Serovar Typhimurium DT104 Invasion is Not Enhanced by Sub-Inhibitory Concentrations of the Antibiotic Florfenicol. J Veterinar Sci Technol 2:104. doi:10.4172/2157-7579.1000104

Copyright: (c 2011 Brunelle BW, et al. This is an open-access article distributed under the terms of the Creative Commons Attribution License, which permits unrestricted use, distribution, and reproduction in any medium, provided the original author and source are credited. 
Citation: Brunelle BW, Bearson SMD, Bearson BL (2011) Salmonella Enterica Serovar Typhimurium DT104 Invasion is Not Enhanced by SubInhibitory Concentrations of the Antibiotic Florfenicol. J Veterinar Sci Technol 2:104. doi:10.4172/2157-7579.1000104

Page 2 of 4

\section{Salmonella invasion assays}

After the 30 minute incubation with or without florfenicol, $1 \mathrm{ml}$ of each sample was centrifuged at $16,000 \mathrm{x}$ g for 2 minutes and resuspended in fresh LB broth to remove the florfenicol. Invasion assays were performed using HEp-2 cells as previously described [16] at a multiplicity of infection of $\sim 40$. Percent invasion was calculated by dividing $\mathrm{CFU} / \mathrm{ml}$ recovered by $\mathrm{CFU} / \mathrm{ml}$ added. Differences in invasion were determined by a one-way ANOVA with Dunnett's post-test to assess pair-wise differences between the no-antibiotic control and the other sample conditions using GraphPad Prism 5 (GraphPad Software, San Diego, CA).

\section{Real-Time PCR assays}

Aliquots for RNA analysis were taken from each bacterial culture immediately after the 30 minute florfenicol incubation and placed in RNAProtect (QIAGEN, Germantown, MD). RNA was isolated using the RNeasy Mini Kit (QIAGEN), and genomic DNA was removed using the Turbo DNase DNA-free kit (Ambion, Austin, TX) according to the directions from the manufacturer. Reverse transcription was carried out using the Applied Biosystems High capacity cDNA reverse transcription kit on total RNA using random primers. Real-Time PCR was performed in a Chromo4 Real-Time PCR Detection System (BioRad Laboratories, Hercules, CA) using the SYBR Green Master Mix (Applied Biosystems, Foster City, CA). Primer sets were used to evaluate the 16S rRNA, floR, hilA, sopB, and pnp genes (Table 1). For control assays, reverse transcriptase was not added to parallel mixtures for each sample. Amplification was performed using the following cycle conditions for each primer set: $95^{\circ} \mathrm{C}$ for $10 \mathrm{~min} ; 40$ cycles of $95^{\circ} \mathrm{C}$ for 15 $\mathrm{s}, 55^{\circ} \mathrm{C}$ for $30 \mathrm{~s}, 72^{\circ} \mathrm{C}$ for $30 \mathrm{~s}$; melting curve analysis from $65^{\circ} \mathrm{C}$ to $95^{\circ} \mathrm{C}$. Raw data was analyzed using LinRegPCR software, and amplification efficiencies and $\mathrm{C}_{\mathrm{T}}$ values were determined using a Window of Linearity for each primer set [17]. Expression differences were calculated by the Pfaffl method (Ratio $=\left(\mathrm{E}_{\text {target }}\right)^{\Delta \mathrm{CTtarget}(\text { control-treated })} /\left(\mathrm{E}_{\text {reference }}\right)^{\Delta \mathrm{CTreference}}$ (control-treated) $)$, where the $16 \mathrm{~S}$ gene was the reference gene and the noantibiotic control culture was the control condition [18]. Values were $\log _{2}$ transformed, and GraphPad Prism 5 was used to perform a onesample T-test with a theoretical mean of 0 to assess differences in gene expression for the samples exposed to florfenicol.

\section{Results and Discussion}

Florfenicol is a drug used for clinical veterinary treatment of respiratory illness, is rapidly absorbed in the animal, and may be administered to animals that are also asymptomatic carriers of Salmonella. To determine if S. Typhimurium DT104 invasion is enhanced following exposure to florfenicol, three clinical bovine isolates and an isogenic mutant lacking the $f l o R$ gene were selected to be studied $\left(530,745,19823\right.$, and $\left.745^{\Delta f l o R}\right)$. All strains were grown to late$\log$ phase in the absence of antibiotics and exposed to $0,1,5$, or $30 \mu \mathrm{g} /$ $\mathrm{ml}$ florfenicol for 30 minutes. These conditions were chosen because exposure to tetracycline for 30 minutes during late-log phase was previously demonstrated to be associated with increased invasiveness [11], whereas longer florfenicol or tetracycline exposure times were not [10]. The florfenicol-treated strains were assessed for differences in invasion compared to the untreated strain by cell culture invasion assays and by real-time PCR expression analyses of genes associated with invasion.

Invasion assays demonstrated that for each strain, no significant difference $(\mathrm{P}<0.05)$ was observed between the no-antibiotic control and all the strains exposed to florfenicol (Figure 1). Although a decrease in invasion in strains 530,745 , and $745^{\Delta f l o R}$ exposed to 5 and 30

\begin{tabular}{|l|l|l|l|}
\hline Gene & Forward Primer & Reverse Primer \\
\hline $16 S$ & CGGGGAGGAGGTGTTGTG & GAGCCCGGGGATTTCACATC & [25] \\
\hline floR & CCACAATTTGGCTGTGATGGCTCA & TGGTCGTGTTATTAGCGGCCAGAT \\
\hline hilA & CGCTGGCAGAATGCTACCTC & AGCCCCAGTAATCCTAAAGCTTG \\
\hline sopB & CGTTGTGCGAGTTTATAGGG & GAGGTCGTCAATACATTAGCG \\
\hline pnp & TGAACCAGACCTTCTTTCC & GAGATCACCGCAGAGATC & This study \\
\hline
\end{tabular}

Table 1: Real-time PCR primers (5'-3').

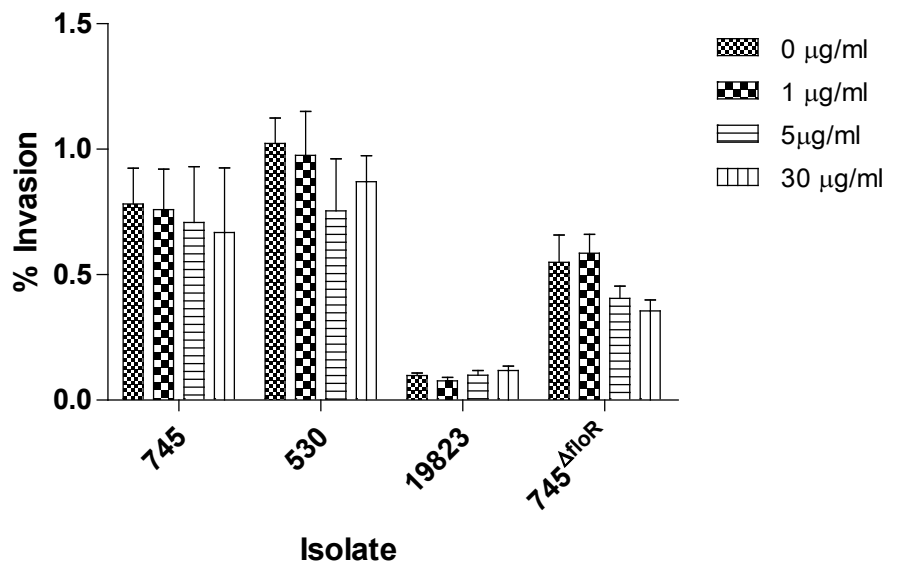

Figure 1: Effect of florfenicol on S. Typhimurium DT104 invasion. Isolates were grown to late-log and then exposed to $0,1,5$, or $30 \mu \mathrm{g} / \mathrm{ml}$ of florfenicol for $30 \mathrm{minutes}$. Invasion assays were performed in HEp-2 cells. 
Citation: Brunelle BW, Bearson SMD, Bearson BL (2011) Salmonella Enterica Serovar Typhimurium DT104 Invasion is Not Enhanced by SubInhibitory Concentrations of the Antibiotic Florfenicol. J Veterinar Sci Technol 2:104. doi:10.4172/2157-7579.1000104

Page 3 of 4

\begin{tabular}{|c|c|c|c|c|c|c|c|c|c|}
\hline \multirow{3}{*}{\begin{tabular}{|l|} 
Strain \\
745 \\
\end{tabular}} & \multirow{3}{*}{\begin{tabular}{|l|} 
Florfenicol \\
$1 \mu \mathrm{g} / \mathrm{ml}$
\end{tabular}} & \multirow{2}{*}{\multicolumn{2}{|c|}{$\begin{array}{l}\text { floR } \\
\text { Log }_{2} \text { change }\left(\mathrm{SEM}^{\dagger}\right)\end{array}$}} & \multirow{2}{*}{\multicolumn{2}{|c|}{$\begin{array}{l}\text { hilA } \\
\text { Log }_{2} \text { change }\left(\mathrm{SEM}^{\dagger}\right)\end{array}$}} & \multirow{2}{*}{\multicolumn{2}{|c|}{$\begin{array}{l}\operatorname{sop} B \\
\log _{2} \text { change }\left(\mathrm{SEM}^{\dagger}\right)\end{array}$}} & \multirow{2}{*}{\multicolumn{2}{|c|}{$\begin{array}{l}\text { pnp } \\
\log _{2} \text { change }\left(\mathrm{SEM}^{\dagger}\right)\end{array}$}} \\
\hline & & & & & & & & & \\
\hline & & 5.21 & $(0.13)^{\star \star \star}$ & 0.23 & $(-0.08)$ & 0.15 & $(0.07)$ & 0.50 & $(0.13)$ \\
\hline & $5 \mu \mathrm{g} / \mathrm{ml}$ & 5.50 & $(0.14)^{\star \star \star}$ & 0.11 & $(0.10)$ & 0.26 & $(0.08)$ & 1.36 & $(0.21)^{*}$ \\
\hline & $30 \mu \mathrm{g} / \mathrm{ml}$ & 5.07 & $(0.09)^{\star \star *}$ & -0.19 & $(0.06)$ & -0.41 & $(0.08)$ & 1.94 & $(0.15)^{\star *}$ \\
\hline \multirow[t]{3}{*}{530} & $1 \mu \mathrm{g} / \mathrm{ml}$ & 5.67 & $(0.21)^{\star \star \star}$ & -0.03 & $(0.12)$ & -0.30 & $(0.18)$ & 0.42 & $(0.09)$ \\
\hline & $5 \mu \mathrm{g} / \mathrm{ml}$ & 5.25 & $(0.19)^{\star \star \star}$ & -0.68 & $(0.15)$ & -0.64 & $(0.19)$ & 1.40 & $(0.18)^{*}$ \\
\hline & $30 \mu \mathrm{g} / \mathrm{ml}$ & 4.82 & $(0.12)^{\star \star \star}$ & -1.05 & $(0.13)^{*}$ & -1.49 & $(0.21)^{*}$ & 1.65 & $(0.14)^{\star *}$ \\
\hline \multirow[t]{3}{*}{19823} & $1 \mu \mathrm{g} / \mathrm{ml}$ & 5.03 & $(0.21)^{\star * *}$ & -0.19 & $(0.10)$ & 0.37 & $(0.13)$ & 0.76 & $(0.06)^{\star *}$ \\
\hline & $5 \mu \mathrm{g} / \mathrm{ml}$ & 5.50 & $(0.11)^{\star \star *}$ & -0.47 & $(0.08)$ & -0.13 & $(0.08)$ & 1.64 & $(0.09)^{\star * *}$ \\
\hline & $30 \mu \mathrm{g} / \mathrm{ml}$ & 4.71 & $(0.06)^{\star \star *}$ & -0.62 & $(0.07)^{\star}$ & -0.07 & $(0.11)$ & 1.54 & $(0.06)^{\star * *}$ \\
\hline \multirow[t]{3}{*}{$745^{\Delta \mathrm{floR}}$} & $1 \mu \mathrm{g} / \mathrm{ml}$ & N/A & & 0.18 & $(0.10)$ & 0.04 & $(0.09)$ & 0.53 & $(0.11)$ \\
\hline & $5 \mu \mathrm{g} / \mathrm{ml}$ & N/A & & -0.22 & $(0.11)$ & -0.49 & $(0.15)$ & 1.10 & $(0.09)^{\star *}$ \\
\hline & $30 \mu \mathrm{g} / \mathrm{ml}$ & N/A & & -0.78 & $(0.07)^{\star \star}$ & -0.75 & $(0.10)^{\star}$ & 1.35 & $(0.06)^{\star \star \star}$ \\
\hline
\end{tabular}

†Standard Error of the Mean; * $\mathrm{P}<0.05 ;{ }^{* *} \mathrm{P}<0.01$; ${ }^{* * *} \mathrm{P}<0.001$

Table 2: Gene expression differences in S. Typhimurium DT104 after exposure to florfenicol relative to control cultures without florfenicol.

$\mu \mathrm{g} / \mathrm{ml}$ florfenicol was observed, it was not significant compared to the controls. Unexpectedly, strain 19823 was not invasive; however, this is now a valuable strain to use as a control for future investigations.

The floR, hilA, $\operatorname{sop} B$, and $p n p$ genes were chosen to assess the effect of florfenicol exposure on expression of invasion-related genes by real-time PCR for the following reasons: FloR mediates florfenicol/ chloramphenicol resistance through an efflux pump [13]; HilA is a transcriptional activator that controls genes on the Salmonella pathogenicity island 1 (SPI-1), is required for invasion, and is regulated by changes in environmental conditions [19]; SopB is an inositol phosphate phosphatase and is necessary for invasion, but it is located outside of SPI-1 and is not directly regulated by HilA [20,21]; PNPase is a polynucleotide phosphorylase that negatively regulates invasion genes in SPI-1 [22,23]. Up-regulation of hilA and $\operatorname{sop} B$ gene expression is associated with increased invasion, while up-regulation of $p n p$ gene expression is associated with decreased invasion. Statistical differences in expression for each gene were determined relative to the no-antibiotic control for each isolate (Table 2). After exposure to florfenicol, there was a significant increase in floR expression for isolates 530, 745, and 19823. The observation that expression of floR is inducible following florfenicol exposure has not been reported previously; only fex $A$, which has no significant homology to $f l o R$, has been shown to be an inducible exporter of both chloramphenicol and florfenicol [9, 24]. There was a significant decrease in hilA expression for strains 530, 19823, and $745^{\Delta f l o R}$ at $30 \mu \mathrm{g} / \mathrm{ml}$, as well as a significant decrease in $\operatorname{sop} B$ expression for strains 530 and $745^{\triangle f l o R}$ at $30 \mu \mathrm{g} / \mathrm{ml}$. All strains had a significant increase in pnp expression at 5 and $30 \mu \mathrm{g} / \mathrm{ml}$, and strain 19823 also had a significant increase in $p n p$ expression at $1 \mu \mathrm{g} / \mathrm{ml}$. After 30 minutes of florfenicol exposure, no transcriptional response for the invasionassociated genes was observed that would increase invasion, which is consistent with the lack of enhanced invasion in the cell culture assays.

In summary, parallel phenotypic and transcriptional analyses indicate that $S$. Typhimurium DT104 invasion was not enhanced after exposure to the antibiotic florfenicol. Concern that using florfenicol to treat respiratory illness will impact the invasiveness of $S$. Typhimurium DT104 in carrier animals is not supported by these results.

\section{Acknowledgements}

We would like to thank Briony Atkinson for exceptional technical assistance as well as Tracy Nicholson, Thomas Casey, and Thaddeus Stanton for critical review of the manuscript. This research was supported by USDA, ARS CRIS funds. Mention of trade names or commercial products in this article is solely for the purpose of providing specific information and does not imply recommendations or endorsement by the US Department of Agriculture. USDA is an equal opportunity provider and employer.

\section{References}

1. Helms M, Ethelberg S, Molbak K, Group DTS (2005) International Salmonella Typhimurium DT104 infections, 1992-2001. Emerging infectious diseases 11: 859-867.

2. Evans S, Davies R (1996) Case control study of multiple-resistant Salmonella typhimurium DT104 infection of cattle in Great Britain. Vet Rec 139: 557-558.

3. Varma JK, Greene KD, Ovitt J, Barrett TJ, Medalla F, et al. (2005) Hospitalization and antimicrobial resistance in Salmonella outbreaks, 1984-2002. Emerg Infect Dis 11: 943-946.

4. Mulvey MR, Boyd DA, Olson AB, Doublet B, Cloeckaert A (2006) The genetics of Salmonella genomic island 1. Microbes Infect 8: 1915-1922.

5. Goh EB, Yim G, Tsui W, McClure J, Surette MG, et al. (2002) Transcriptional modulation of bacterial gene expression by subinhibitory concentrations of antibiotics. Proc Natl Acad Sci U S A 99: 17025-17030.

6. Blickwede M, Goethe R, Wolz C, Valentin-Weigand P, Schwarz S (2005) Molecular basis of florfenicol-induced increase in adherence of Staphylococcus aureus strain Newman. J Antimicrob Chemother 56: 315-323.

7. Deneve C, Bouttier S, Dupuy B, Barbut F, Collignon A, et al. (2009) Effects of subinhibitory concentrations of antibiotics on colonization factor expression by moxifloxacin-susceptible and moxifloxacin-resistant Clostridium difficile strains. Antimicrob Agents Chemother 53: 5155-5162.

8. Kuroda H, Kuroda M, Cui L, Hiramatsu K (2007) Subinhibitory concentrations of beta-lactam induce haemolytic activity in Staphylococcus aureus through the SaeRS two-component system. FEMS Microbiol Lett 268: 98-105.

9. Schwarz S, Kehrenberg C, Doublet B, Cloeckaert A (2004) Molecular basis of bacterial resistance to chloramphenicol and florfenicol. FEMS Microbiol Rev 28: $519-542$

10. Carlson SA, Willson RM, Crane AJ, Ferris KE (2000) Evaluation of invasionconferring genotypes and antibiotic-induced hyperinvasive phenotypes in multiple antibiotic resistant Salmonella typhimurium DT104. Microb Pathog 28 373-378.

11. Weir EK, Martin LC, Poppe C, Coombes BK, Boerlin P (2008) Subinhibitory concentrations of tetracycline affect virulence gene expression in a multi- 
Citation: Brunelle BW, Bearson SMD, Bearson BL (2011) Salmonella Enterica Serovar Typhimurium DT104 Invasion is Not Enhanced by SubInhibitory Concentrations of the Antibiotic Florfenicol. J Veterinar Sci Technol 2:104. doi:10.4172/2157-7579.1000104

resistant Salmonella enterica subsp. enterica serovar Typhimurium DT104. Microbes Infect 10: 901-907.

12. Shen L, Shi Y, Zhang D, Wei J, Surette MG, et al. (2008) Modulation of secreted virulence factor genes by subinhibitory concentrations of antibiotics in Pseudomonas aeruginosa. J Microbiol 46: 441-447.

13. Boyd D, Peters GA, Cloeckaert A, Boumedine KS, Chaslus-Dancla E, et al. (2001) Complete nucleotide sequence of a 43-kilobase genomic island associated with the multidrug resistance region of Salmonella enterica serovar Typhimurium DT104 and its identification in phage type DT120 and serovar Agona. J Bacteriol 183: 5725-5732.

14. Datsenko KA, Wanner BL (2000) One-step inactivation of chromosomal genes in Escherichia coli K-12 using PCR products. Proc Natl Acad Sci U S A 97: 6640-6645.

15. Lee CA, Falkow S (1990) The ability of Salmonella to enter mammalian cells is affected by bacterial growth state. Proc Natl Acad Sci U S A 87: 4304-4308.

16. Elsinghorst EA (1994) Measurement of invasion by gentamicin resistance. Methods Enzymol 236: 405-420.

17. Ramakers C, Ruijter JM, Deprez RH, Moorman AF (2003) Assumption-free analysis of quantitative real-time polymerase chain reaction (PCR) data. Neurosci Lett 339: 62-66.

18. Pfaffl MW (2001) A new mathematical model for relative quantification in realtime RT-PCR.. Nucleic Acids Res 29: e45.
19. Bajaj V, Lucas RL, Hwang C, Lee CA (1996) Co-ordinate regulation of Salmonella typhimurium invasion genes by environmental and regulatory factors is mediated by control of hilA expression. Mol Microbiol 22: 703-714.

20. Eichelberg K, Galan JE (1999) Differential regulation of Salmonella typhimurium type III secreted proteins by pathogenicity island 1 (SPI-1)encoded transcriptional activators InvF and HilA. Infect Immun 67: 4099-4105.

21. Norris FA, Wilson MP, Wallis TS, Galyov EE, Majerus PW (1998) SopB, a protein required for virulence of Salmonella dublin, is an inositol phosphate phosphatase. Proc Natl Acad Sci U S A 95: 14057-14059.

22. Altier C (2005) Genetic and environmental control of salmonella invasion. $J$ Microbiol 43 Spec No: 85-92.

23. Clements MO, Eriksson S, Thompson A, Lucchini S, Hinton JC, et al. (2002) Polynucleotide phosphorylase is a global regulator of virulence and persistency in Salmonella enterica. Proc Natl Acad Sci U S A 99: 8784-8789.

24. Kehrenberg C, Schwarz S (2004) fexA, a novel Staphylococcus lentus gene encoding resistance to florfenicol and chloramphenicol. Antimicrob Agents Chemother 48: 615-618.

25. Chang HR, Loo LH, Jeyaseelan K, Earnest L, Stackebrandt E (1997) Phylogenetic relationships of Salmonella typhi and Salmonella typhimurium based on 16S rRNA sequence analysis. Int J Syst Bacteriol 47: 1253-1254.

26. Golding GR, Olson AB, Doublet B, Cloeckaert A, Christianson S, et al. (2007) The effect of the Salmonella genomic island 1 on in vitro global gene expression in Salmonella enterica serovar Typhimurium LT2. Microbes Infect 9: 21-27. 